\title{
Measuring the Land Use Based Risk of Soil Erosion in a Mining-Dominated Landscape in Northern Iran
}

\author{
Nosratollah Layeghi ${ }^{1}$, Seyed Akbar Javadi ${ }^{*}$, Mohammad Jafari² $^{2}$, Hossein Arzani ${ }^{2}$ \\ 1 Department of Range Management, Science and Research Branch, Islamic Azad University, Tehran, Iran \\ 2 Faculty of Natural Resources, University of Tehran, Karaj, Iran \\ * Corresponding author's e-mail: a.javadi@srbiau.ac.ir
}

\begin{abstract}
This study assessed the occurrence risk of soil erosion in a mining-dominated landscape in Qazvin Province, northern Iran using the Land Use Impact Model (LUIM) and MPSIAC model. The LUIM employs two concepts for estimating the soil erosion risk: Likelihood and Consequence. Likelihood was estimated spatially by integrating the maps of soil susceptibility to erosion, derived from a simultaneous analysis of slope, runoff curve number, and NDVI maps, and current land use management practices. In turn, Consequence was measured by combining soil sensitivity to erosion (according to soil depth), and the socio-economic and environmental value of different land uses. Likelihood was found to be high over abandoned rainfed and mining lands and low in rangelands. All mining areas and parts of rainfed lands and rangelands, covering $35 \%$ of the region, were classified as high in terms of Consequence. According to the final soil risk map, over $60 \%$ of the region distributed across all mining areas and parts of rangelands as well as the rainfed and irrigated lands, was found to have a moderate risk of soil erosion. The results showed that the ratio of mining sizes to their relevant hydrological basins size had a significant correlation with specific erosion, and special sediment $(p<0.01)$. Overall, extensive surface mining activities were found to be a major soil erosion driver requiring effective post-mining rehabilitation plans.
\end{abstract}

Keywords: land use impact model, mining areas, rangeland, risk assessment, soil erosion likelihood, MPSIAC

\section{INTRODUCTION}

Soil is a natural entity, providing organisms with food and habitat and plants with essential nutrients (Colazzo et al., 2017). As a complex system, soil is composed of highly dynamic structural/ physical components, the characteristics of which vary considerably, even with slight changes in the condition of ecological (such as climate; see Rousk et al. (2016)) and anthropogenic (such as management policies; see Fink et al. (2016)) factors. Soil erosion is a slow but continual process of soil loss arising from constant interactions with many soil-eroding factors, with some that can be readily controlled by management such as informed land-use allocation (Colazzo et al., 2017). The soil erosion-related consequences are widespread and varied in type, such as decreasing farm-business profitability (Toy et al., 2002), disturbing global biogeochemical cycles (Cerdan et al., 2010), increasing non-point pollution and sedimentation (Verstraeten et al., 2002) and degrading water utility (Lakhote et al., 2014; Hou et al., 2020). The magnitude of soil erosion, both by wind and water, differs among ecosystems. In some regions, soil erosion is increasingly seen as a serious concern and attracted the special attention of policy-makers and even the public (Renschler and Harbor, 2002). For instance, the soil erosion in Iran, as an arid and semi-arid country, amounts to 24 to 40 tons per hectare per year, equating to two to five times greater than the acceptable global rate (Ostovari et al., 2016).

Unsustainable land use/land cover (LU/LC) allocation has continuously been portrayed as a major threat to soil erosion (Ochoa-Cueva et al., 2015; Wang et al., 2016). Land-use intensification and improper planning of LU/LCs allow soil 
erosion and sediment transport factors to play a more significant role in the land resource degradation (Bakker et al., 2008). The previous research attention to the effect of LU/LC change on soil erosion and the attendant economic/ ecological consequences has been primarily oriented towards the conversion of natural LU/LC (e.g., rangeland and forests) to agriculture (Borrelli et al., 2017) as well as mining and mine-related land-use activities (Martín-Moreno et al., 2016; Zhang et al., 2016; Zhang et al., 2015). The soil erosion risk caused by mining is considerably high, resulting from a combination of certain mine-related activities and processes such as eradication of natural vegetation and production of high loads of eroded materials (Wantzen and Mol, 2013; Suh et al., 2017). By focusing on these effects, Kim et al. (2012), for example, used the universal soil loss equation model to estimate the soil erosion and sediment yield from mine tailing dumps of a mine-dominated landscape in Korea and found that mining activities contributed to a significant proportion of sediment transport during storm events. Yin et al. (2016) also assessed the soil erosion under different land uses in a human-dominated region in Southwest Guizhou Province, China using the RUSLE model and GIS spatial analysis method. They recognized the private-owned coal mines as the most sensitive areas to soil erosion, requiring more vigilant protection. Despite these consequences, however, mining activities have substantially expanded worldwide. Small-scale surface mining is one of the most common types of these activities, the adverse impacts of which on the environment have been less explored in some parts of the globe, particularly in Iran, where they are exempted from the Environmental Impact Assessment (EIA) procedures.

The above-mentioned issues underscore the importance of developing a holistic body of knowledge regarding the impacts of small-scale surface mines on the environment. A range of methods has been developed for dealing with this concern (Demir et al., 2018; Gholami et al., 2018), with each having its own merits and challenges. The majority of these methods allow estimating the amount and probability of soil erosion (such as MPSIAC and USLE) while failing to involve the value and role of the associated LU/ LCs. Land Use Impact Model (LUIM) is a promising approach in this regard, enabling users to incorporate the likelihood-consequence coupled impacts of soil erosion through a spatially explicit manner (see section 2.2 for a detailed description of LUIM). Relying on this method, McNeill et al. (2006) prioritized the actions for soil erosion management in West Gippsland, Australia. Specifically, they combined six soil erosion processes under current land management regimes to identify the highly valuable assets to be conserved from further soil erosion-related degradation. Clark et al. (2010) used the remote sensing techniques to provide this risk assessment framework with the required input data and the subsequent generation of a regional wind erosion-induced land degradation map in the Mallee region, Australia. In order to contribute to this research line, the parameters describing land sensitivity and Likelihood to soil erosion were identified and mapped for a miningdominated landscape in northern Iran. The LUIM and MPSIAC models were then employed to measure and compare the occurrence risk of soil erosion from various LU/LCs, especially the surface mining areas.

\section{MATERIAL AND METHODS}

\section{Study area}

The Moradbigloo watershed in Qazvin Province, northern Iran, was selected as the study area of this research (Fig. 1). This region is situated between $35^{\circ} 40^{\prime} 35^{\prime \prime}-35^{\circ} 48^{\prime} 33^{\prime \prime} \mathrm{N}$ longitude and $49^{\circ} 36^{\prime} 27^{\prime \prime}-49^{\circ} 44^{\prime} 58^{\prime \prime}$ E latitude in zone $39 \mathrm{~N}$ (at $160 \mathrm{~km}$ from Tehran, the capital of Iran) and has an area extension of 11350.9 ha, of which rangelands occupy 7193 ha (63.4\%), and 122.4 ha is exposed to mining activities. The region has a wide altitudinal gradient increasing northward from $1530 \mathrm{~m}$ to $2200 \mathrm{~m}$. The study area has an annual precipitation of $320 \mathrm{~mm}$ with spring as the rainiest season, which receives over $36 \%$ of the annual precipitation. According to De Martonne, the study area has a cold semi-arid climate. In summer, the study area has a relatively arid climate, receiving less than $4 \%$ of the annual precipitation. The air temperature of the study area is relatively low (an annual mean of $11.9^{\circ} \mathrm{C}$ ), and it comes below the freezing temperature for averagely 112 days of the year occurring during early December to late February.

\section{Land use impact model description}

LUIM was developed by a group of Australian scientists to identify and rank areas at risk 

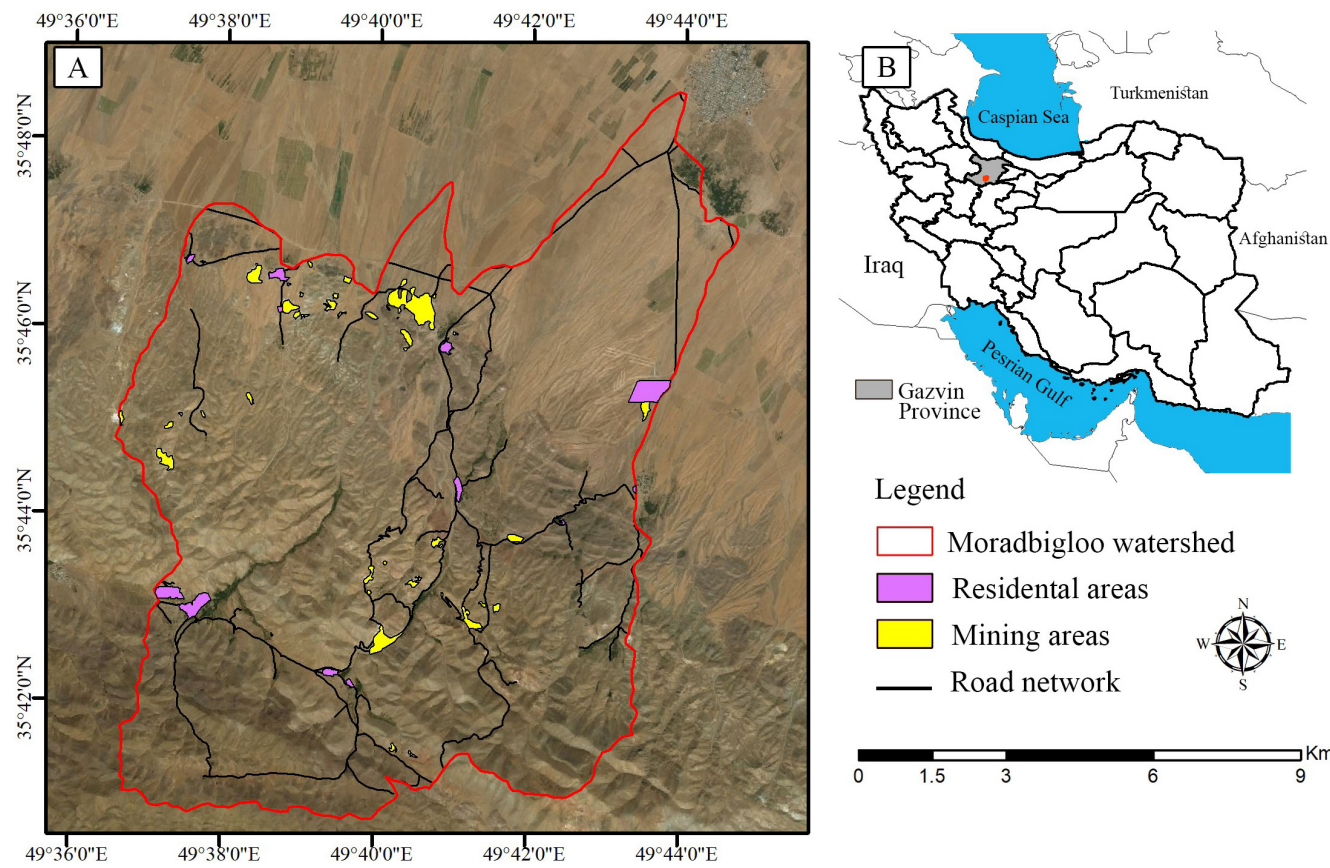

Legend

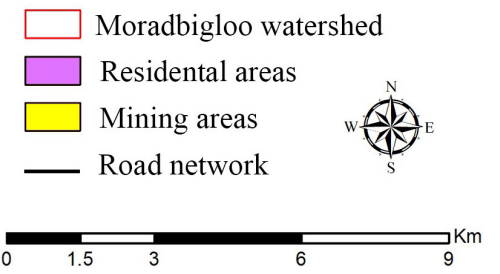

Fig. 1. a) Study area: Moradbigloo watershed, b) location of the study area in Iran

of soil degradation and vegetation loss across broad geographical levels. This model involves both spatial and non-spatial components. Within the spatial context, a GIS environment is utilized to map the occurrence extent of these attributes. The non-spatial component includes developing the knowledge about the implemented land management practices, threats, and landscape attributes (McNeill et al., 2006). These components are then integrated through the LUIM framework to delineate the occurrence risk of a particular threatening event per area unit. Risk assessment in this model is performed by combining two data layers representative of the occurrence chance of an event (known as Likelihood) and the magnitude of its collateral consequences (Consequence) (McNeill et al., 2006; Kuchami-Sardo et al., 2020). The former data layer, Likelihood, is constructed by integrating the data indicating how land is managed to mitigate the potential adverse impacts of the threatening event (Management) and the chance or the magnitude (\%) at which the event may reach its critical threshold (Susceptibility). The latter one, Consequence, is defined by the productivity and quality of the asset (Value) and the dysfunctional influence of an event on the asset (Sensitivity). The LUIM outputs are categorical maps representing the probability of occurrence, the severity of impact, and the risk of a threatening event per area unit. Figure 2 shows a schematic drawing of risk assessment using LUIM.

\section{LUIM INPUT PREPARATION}

\section{Susceptibility}

There are plenty of potential factors affecting the soil susceptibility to erosion, the contribution of which is site-specific and differ between regions, leaving no general method to evaluate erosion susceptibility (Abdulkadir et al., 2019). Regarding this matter and the region's

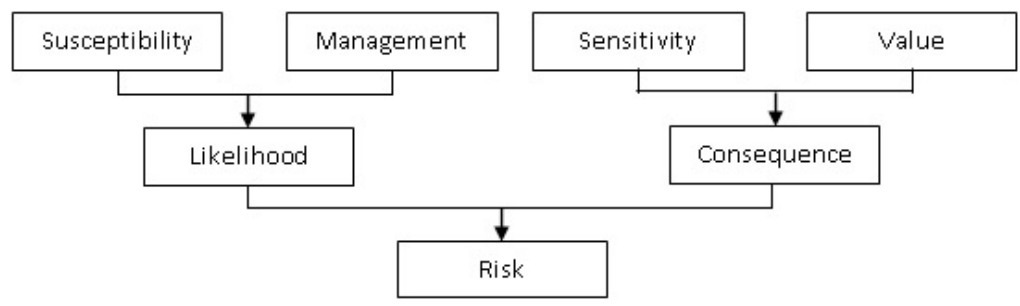

Fig. 2. Schematic diagram of occurrence risk assessment using Land Use Impact Model (LUIM) 
characteristics, three factors were identified as important for estimating the soil susceptibility: slope, runoff curve number, and normalized difference vegetation index (NDVI) derived from a Landsat image in July 2015. The classification scheme applied to these factors is as follow:

- Low susceptibility: areas with a slope between $0-15 \%$, runoff curve number of 39 , and NDVI of 0.29 .

- Moderate susceptibility: areas with a slope between $15-30 \%$, runoff curve number of 69 , and NDVI of 0.22 .

- High susceptibility: areas with a slope between $30-60 \%$, runoff curve number of 84 , and NDVI of 0.18 .

\section{Management}

As an important advantage, LUIM considers three levels of LU/LC management practices or combinations of practices to investigate the effect of alternative land management scenarios on the risk of soil erosion. A Landsat-based derived LU/LC with four classes (see table 1) produced in 2015 was used as the input layer of this parameter. The unavailability of the data on the land management practices led us to rely on experts for estimating the potential influence of LU/LCs and their respective practices on soil erosion. The garden and irrigated agriculture were found to be primarily affected by the type of irrigation (flooding and drip irrigation) and the amount of fertilizer. The amount of rainfall and the tillage direction were identified as the most influential practices leading to soil erosion. In rangelands, soil erosion was supposed to be significantly influenced by the vegetation cover and the type of improvement practices. The intensity of mining activities and the type of rehabilitation plan undertaken after the cease of mining operation were considered as the most salient practices contributing to soil erosion. This information, along with their relative degradation potential (\%) to soil erosion, was imported to the LUIM model as separate tables for each LU/LC type to delineate the management map (Table 1).

\section{Sensitivity}

Sensitivity to degradation is defined as the soil resilience to, or recovery from, erosion (McNeill et al., 2006). Soil sensitivity to erosion stems from a broad but area-specific set of factors. Among them, soil depth was frequently

Table 1. Land use/land cover types, their management practices and degradation potential (\%) to soil erosion

\begin{tabular}{|c|c|c|c|}
\hline \multirow{2}{*}{ LU/LC types } & \multicolumn{3}{|c|}{ Practice } \\
\hline & Type & Level & Land proportion (\%) \\
\hline \multirow{5}{*}{$\begin{array}{l}\text { Gardens and irrigated } \\
\text { agriculture }\end{array}$} & \multirow{2}{*}{ Irrigation } & Drip & 20 \\
\hline & & Flooding & 80 \\
\hline & \multirow{3}{*}{ Fertilizing } & Low & 5 \\
\hline & & Medium & 35 \\
\hline & & High & 60 \\
\hline \multirow{5}{*}{ Rainfed agriculture } & \multirow{2}{*}{ Tillage direction } & Parallel to the slope direction & 80 \\
\hline & & Perpendicular to the slope direction & 20 \\
\hline & \multirow{3}{*}{ Rainfall } & Low & 35 \\
\hline & & Medium & 50 \\
\hline & & High & 10 \\
\hline \multirow{6}{*}{ Rangeland } & \multirow{3}{*}{ Vegetation cover } & Low $(<20 \%)$ & 20 \\
\hline & & Medium (20- $30 \%)$ & 30 \\
\hline & & High $(30-40 \%)$ & 50 \\
\hline & \multirow{3}{*}{ Improvement practices } & No effort & 33 \\
\hline & & Cultivation of almonds & 33 \\
\hline & & Seeding & 33 \\
\hline \multirow{6}{*}{ Mining } & \multirow{3}{*}{ Intensity } & Low & 25 \\
\hline & & Medium & 35 \\
\hline & & High & 40 \\
\hline & \multirow{3}{*}{$\begin{array}{l}\text { Rehabilitation efforts after } \\
\text { cease of mining }\end{array}$} & No effort & 33 \\
\hline & & Low & 33 \\
\hline & & High & 33 \\
\hline
\end{tabular}


reiterated as a paramount factor in determining the land sensitivity to soil erosion (Dortmans et al., 2006; McNeill and MacEwan 2007) in which the thinner the topsoil indicates the lower resilience (higher sensitivity) to soil erosion. In order to produce the sensitivity layer, the soil map of the region was classified into three classes of low sensitivity (soil depth of $>20 \mathrm{~cm}$ ), moderate sensitivity (soil depth between 10-20 cm), and high sensitivity (soil depth of $<10 \mathrm{~cm}$ ).

\section{Value}

This study relied on the opinions of experts to better explore the value of LU/LC asset values. Despite being a highly profitable activity, mining areas were given an economic value of "low", because the income emanated by this activity is not unobservable by and does not spread to the local community. Rangelands, however, require relatively low energy input and have the highest income-generating potential among the LU/LCs of the region. Moreover, rangelands have a multitude of environmental values, especially in terms of soil protection, while the mining activities provoke soil erosion. According to the experts' opinions, low, moderate, and high value were assigned to, mines, rainfed and irrigated agriculture and gardens, and rangelands, respectively.

\section{Likelihood, consequence, and risk analysis}

The LUIM input parameters consisting of Susceptibility, Management, Sensitivity, and Value were combined using the model framework to delineate the Likelihood, Consequence, and Risk maps. This model estimates the Likelihood of soil erosion occurrence based on a matrix built by joining the management practices and susceptibility values (McNeill et al., 2006; Kuchemi et al., 2020) (Table 2). The resulting maps were then interpreted to determine how the region is exposed to the risk of soil erosion by emphasizing the extensive mining activities that took place in the study area.

\section{Measuring erosion using MPSIAC}

In the MPSIAC model, nine factors including surface geology (Y1), soil (Y2), climate (Y3), runoff (Y4), topography (Y5), land cover (Y6), land use (Y7), upland erosion (Y8) and channel erosion (Y9) were used to measure the soil erosion and the rate of sediment yield in each hydrological basin (Table 3) (Johnson and Gebhardt, 1982; Noori et al., 2018).

Specific values were assigned to the nine factors in the MPSIAC model in each hydrological basin, and sediment delivery (R) of the studied area was calculated by the sum of these scores.

Table 2. Likelihood of erosion occurrence by joining land management and susceptibility, VL - very low, L - low, $\mathrm{M}$ - moderate, $\mathrm{H}$ - high and $\mathrm{VH}$ - very high

\begin{tabular}{|l|c|c|c|c|c|}
\hline \multirow{2}{*}{ Management practices } & \multicolumn{5}{c|}{ Susceptibility } \\
\cline { 2 - 6 } & $\mathrm{VL}$ & $\mathrm{L}$ & $\mathrm{M}$ & $\mathrm{H}$ & $\mathrm{VH}$ \\
\hline Strongly negative & $\mathrm{VL}$ & $\mathrm{L}$ & $\mathrm{M}$ & $\mathrm{VH}$ & $\mathrm{VH}$ \\
\hline Moderately negative & $\mathrm{VL}$ & $\mathrm{L}$ & $\mathrm{L}$ & $\mathrm{H}$ & $\mathrm{VH}$ \\
\hline Weakly negative & $\mathrm{VL}$ & $\mathrm{VL}$ & $\mathrm{VL}$ & $\mathrm{M}$ & $\mathrm{H}$ \\
\hline Neutral & $\mathrm{VL}$ & $\mathrm{VL}$ & $\mathrm{VL}$ & $\mathrm{L}$ & $\mathrm{L}$ \\
\hline Beneficial & $\mathrm{VL}$ & $\mathrm{VL}$ & $\mathrm{VL}$ & $\mathrm{L}$ & $\mathrm{L}$ \\
\hline
\end{tabular}

Table 3. Effective factors on the erosion in the MPSIAC model (Johnson and Gebhard, 1982)

\begin{tabular}{|c|l|c|l|}
\hline No & \multicolumn{1}{|c|}{ Effective factors } & Equation & \multicolumn{1}{c|}{ Description } \\
\hline 1 & Surface geology & $\mathrm{Y} 1=\mathrm{X} 1$ & $\mathrm{X} 1=$ Stones sensitivity to erosion $(0-10)$ \\
\hline 2 & Soil & $\mathrm{X} 2=16.67 \mathrm{~K}$ & $\mathrm{~K}=$ soil erodibility \\
\hline 3 & Climate & $\mathrm{X} 3=0.2 \mathrm{P} 2$ & $\mathrm{P} 2=6-$ hour rainfall with 2 - year return period \\
\hline 4 & Runoff & $\mathrm{X} 5=0.006 \mathrm{R}+10 \mathrm{Qp}$ & $\begin{array}{l}\mathrm{R}=\text { runoff height } \\
\mathrm{QP}=1-\text { year specific pick discharge }\end{array}$ \\
\hline 5 & Topography & $\mathrm{X} 6=0.2 \mathrm{~Pb}$ & $\mathrm{~S}=$ slope $(\%)$ \\
\hline 6 & Land cover & $\mathrm{X} 7=20-0.2 \mathrm{Pc}$ & $\mathrm{Pc}=$ bare ground percent \\
\hline 7 & Land use & $\mathrm{X} 8=0.25 \mathrm{SSF}$ & $\mathrm{SSF}=$ the score of soil surface erosion in the BLM method \\
\hline 8 & Surface erosion & $\mathrm{X} 9=1.67 \mathrm{SSF}$ & $\mathrm{SSFg}=$ the score of gully erosion in the BLM method \\
\hline 9 & Gully erosion & &
\end{tabular}


The following equation was used to calculate specific sediment in cubic meters per square kilometer per year.

$$
Q s=38.77 \mathrm{e} 0.0353 R
$$

where: $Q s-$ Special sedimentation rate in $\mathrm{km}^{2} \mathrm{~m}^{3}$

$R$ - Sedimentation rate per hydrological sub-basin, e - logarithm base

Sediment delivery ratio (SDR) is a ratio that indicates the deposition percentages from the eroded soils and is calculated as follows:

$S D R=$ Special sediment/special erosion

$$
\log S D R=1.8768-0.14191 \log 10 \mathrm{~A}
$$

where: SDR - Sediment yield ratio in percent, A - Area in square mile.

The special erosion was determined using the delivery ratio of sediment deposition and special erosion in each hydrological basin.

In order to investigate whether the size of mines is correlated with erosion, the proportion of the mine site size to their basins size was calculated. Then, the correlations of this ratio to the special erosion, special sediment, total sediment, total erosion, and SDR were tested.

\section{Monitoring vegetation cover before and after mining activities}

The vegetation index map (NDVI) was compared before and after the construction of mines in the region. The Landsat MSS satellite image was taken from July in 1980 and the TM image in July 2017 from the study area, and the NDVI index was calculated over 37 years using equation 4 :

$$
N D V I=(\mathrm{Nir}-\mathrm{Red}) /(\mathrm{Nir}+\mathrm{Red})
$$

where: Red - spectral reflectance measurements acquired in the red (visible) band

Nir - spectral reflectance measurements acquired at near-infrared band.

\section{RESULTS}

LUIM was executed using all input maps and the related classification tables. The resulting categorical Susceptibility, Management, Sensitivity, and Value maps as well as the percentage area occupied by each class (low, moderate, and high) are illustrated in Figure 3 and Table 4, respectively. Susceptibility to erosion was moderate for most parts of the study area (64.1\% of the total area), distributed across the northern and southern regions as well as along the streams that are covered by the garden and irrigated agricultural fields. Land management was poor for the most substantial proportion of the study area (over 57\%) in low elevated rainfed agricultural lands and mining areas. Nearly $32 \%$ (3678 ha) of the region where land is occupied by steep rangelands, have a good management condition. The garden and irrigated agricultural areas constituted a small part of the region that was identified to have moderate management.

The land sensitivity to soil erosion was found to be high over mining areas, irrigated streams and plain rainfed lands (3946.1 ha and $34.7 \%$ of the study area), moderate over highland rangelands and rainfed areas (1492.2 ha and $13.1 \%$ of the study area) and low over foothill rangelands (5608.1 ha and $49.9 \%$ of the study area) (Fig. 3). According to the opinions of experts, the majority of the study area had a high Value (over 63\%, around 7180 ha). The abandoned farmlands in the north and mining areas with a total area of around 3320 ha $(29.2 \%$ of the total area) obtained a low Value. The garden and irrigated agricultural lands which cover only a small proportion of the study region (4.8\%) fell into moderate Value class. By coupling Susceptibility and Management, LUIM assigned approximately equal areas to each class of Likelihood (Fig. 3). As expected, the LUIM model characterized abandoned rainfed and mining lands as areas with high soil erosion likelihood while giving low soil erosion likelihood to steep rangelands. The coupled sensitivity and value parameters, known as Consequence, was found to be moderate across $24.1 \%$ of the study area, and high over most of the study area (nearly 7800 ha (69\%) of the study area) including mining areas, parts of rainfed areas and rangelands.

A soil erosion risk map was the ultimate outcome of the analysis undertaken in this research (Fig 3). As shown in Table 4, the largest part of the study area (over $60 \%$ of the region) had a moderate risk of soil erosion which was distributed across parts of rangelands and rainfed and irrigated lands while all mining areas were classified as regions with a high risk of soil erosion. This finding, along with the insufficient attention being currently paid to the role of mining activities on the environment, 
Table 4. Area of LUIM parameters into three low, moderate, and high classes in the study area except rocks $(2.8 \%$ of the study area is covered by rocks)

\begin{tabular}{|l|c|c|c|}
\hline \multirow{2}{*}{ LUIM parameters } & \multicolumn{3}{|c|}{ Area in ha (\%) } \\
\cline { 2 - 4 } & Low & Moderate & High \\
\hline Susceptibility & $479.7(4.2)$ & $7277.3(64.1)$ & $3289.4(28.9)$ \\
\hline Management & $6475.1(57.1)$ & $893.2(7.7)$ & $3678.1(32.4)$ \\
\hline Sensitivity & $5608.1(49.4)$ & $1492.2(13.1)$ & $7179.6(63.2)$ \\
\hline Value & $3319.8(29.2)$ & $547.0(4.8)$ & $3609.2(31.7)$ \\
\hline Likelihood & $3760.5(33.1)$ & $3676.7(32.4)$ & $7844.6(69.0)$ \\
\hline Consequence & $465.8(4.1)$ & $2940.0(24.1)$ & $3966.1(34.9)$ \\
\hline Risk & $90.2(0.7)$ & $6990.1(61.6)$ & \\
\hline
\end{tabular}

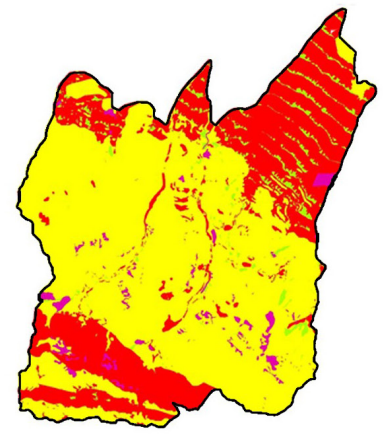

Susceptibility

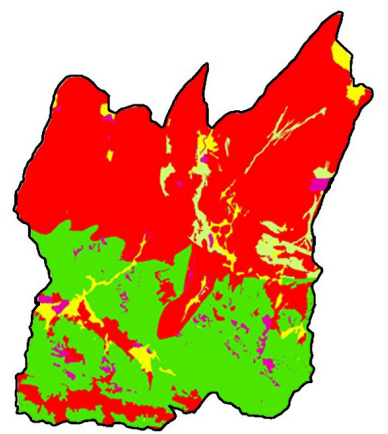

Management

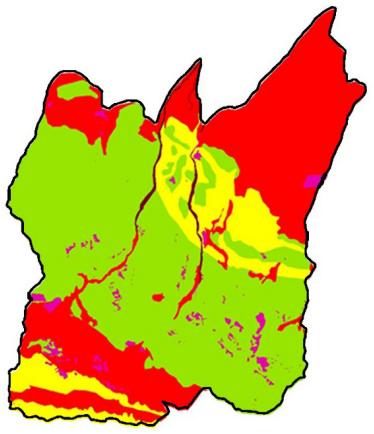

Sensitivity

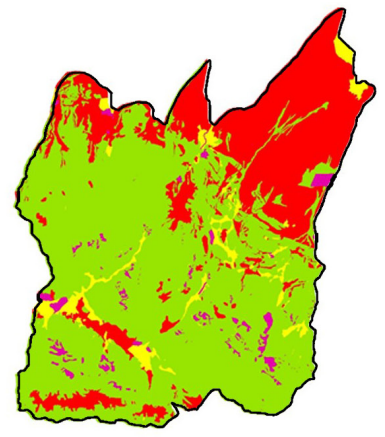

Value

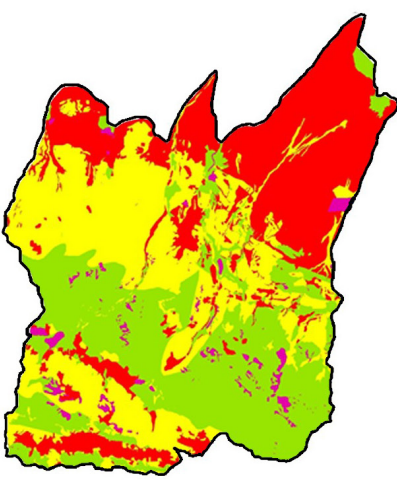

Likelihood

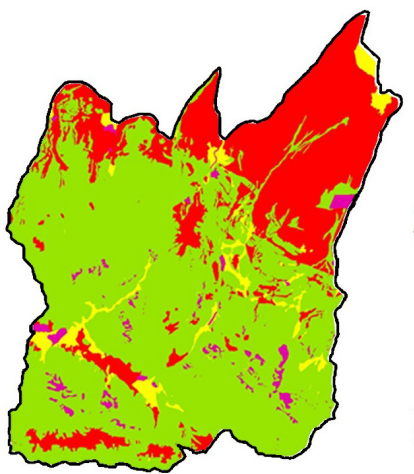

Consequence

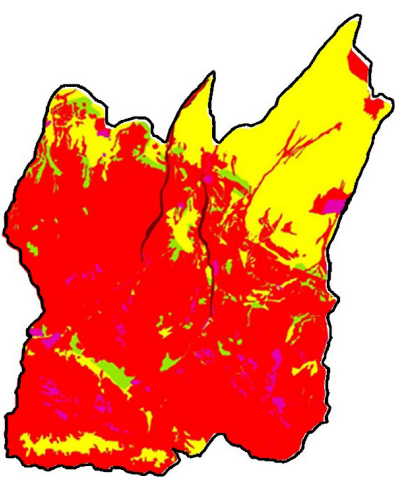

Risk

\section{Legend}

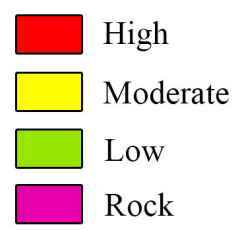

Fig. 3. Maps of LUIM parameters into three low, moderate, and high classes especially towards their contribution in increased soil erosion, highlight their critical importance and revision of regulations that exempted them from Environmental Impact Assessment procedures.

The results showed that the ratio of mining to the size of the hydrological basin had significant correlation with specific erosion and special sediment $(p<0.01)$ (Fig. 4). The results indicated that the amount of special erosion and special sediment increase along with the ratio of mining to the sub-basins size. There was no significant correlation between this ratio and total erosion, total sediment, and sediment delivery ratio in the hydrological basins.
According to the NDVI maps, the vegetation cover was decreased considerably between July 1980 to 2017 before and after mine exploitation, respectively. If the study area remained unchanged and used as rangeland, the risk of erosion was less likely because they had adequate coverage and less $\mathrm{CN}$ than mining (Fig. 5).

According to the results of MPSIAC, the special erosion varied between 1.66 to 9.21 tons per hectare in the study area. The results also showed higher soil erosion in the hydrological basins with the mining operation (Fig. 6) (see MO5-1-1 versus MO6-1 hydrological basins in the south parts of the study area, and MO5-2 versus MO5-int in north parts of the study area). 

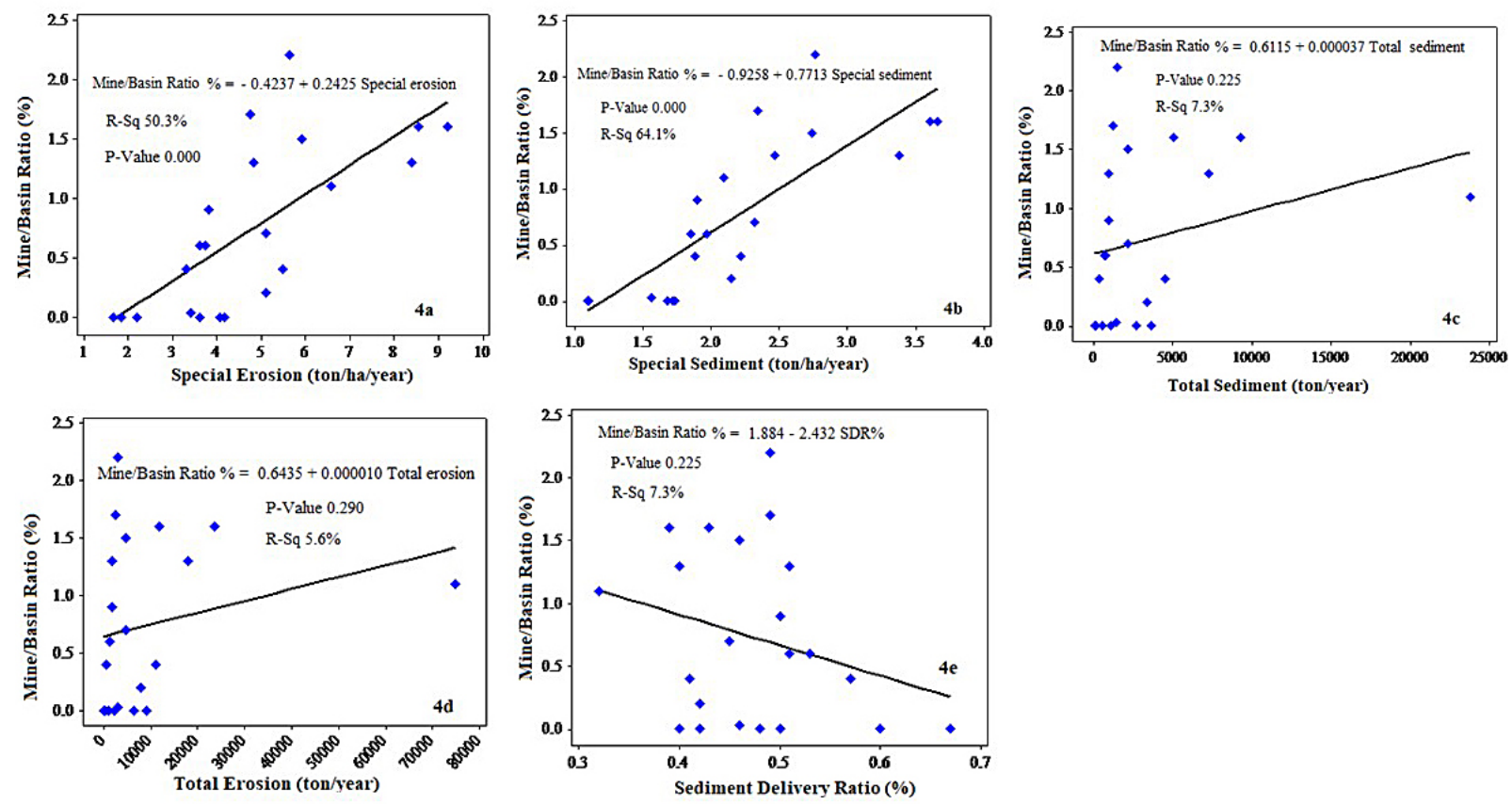

Fig. 4. The correlation of the ratio of mines size to the sub-basins size to (a) special erosion,

(b) special sediment, (c) total sediment, (d) total erosion, and (e) Sediment delivery ratio
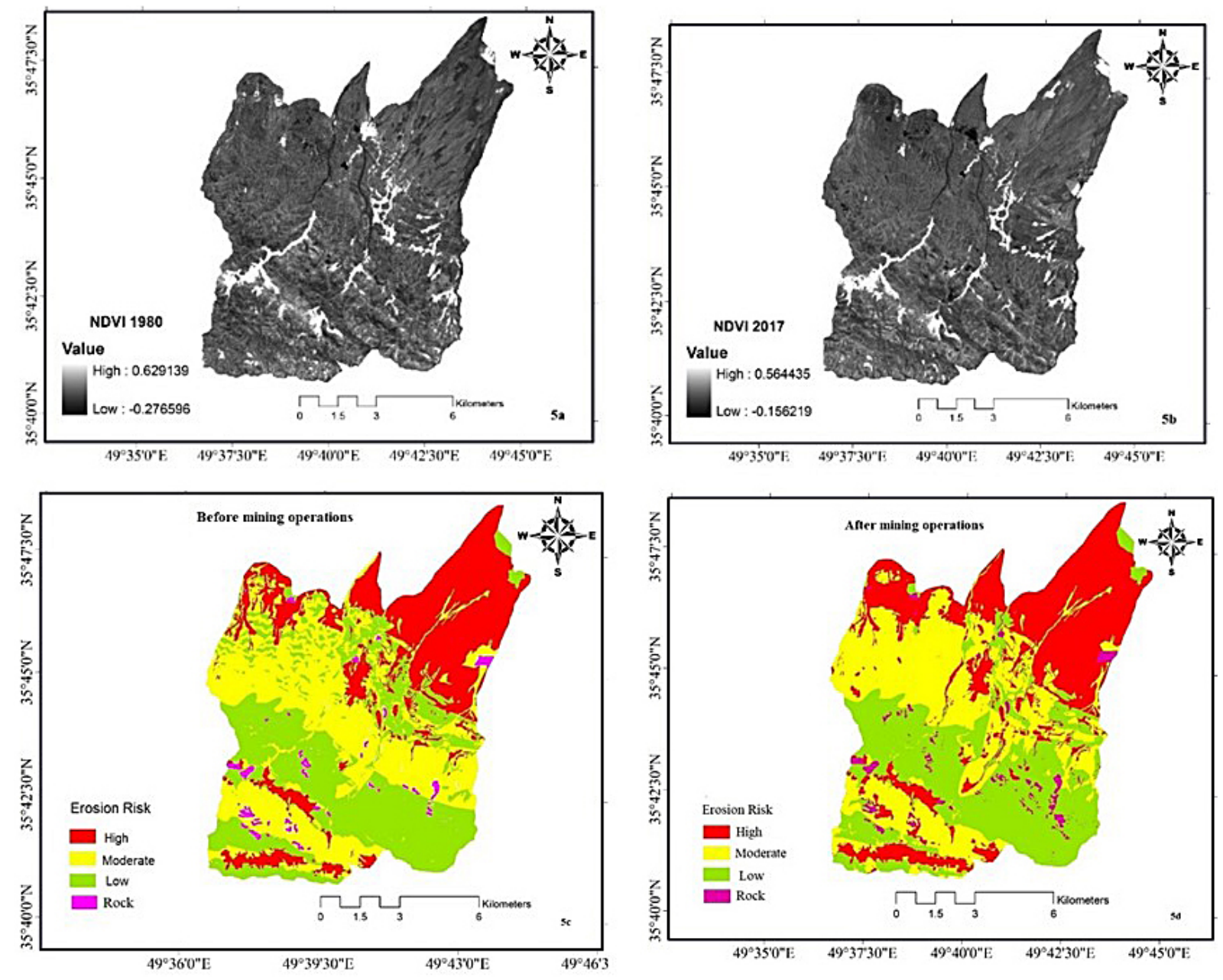

Fig. 5. The different vegetation cover based on NDVI index (a) July 1980 (b) July 2017 and its erosion risk (c) before mining operations, and (d) after mining operations 


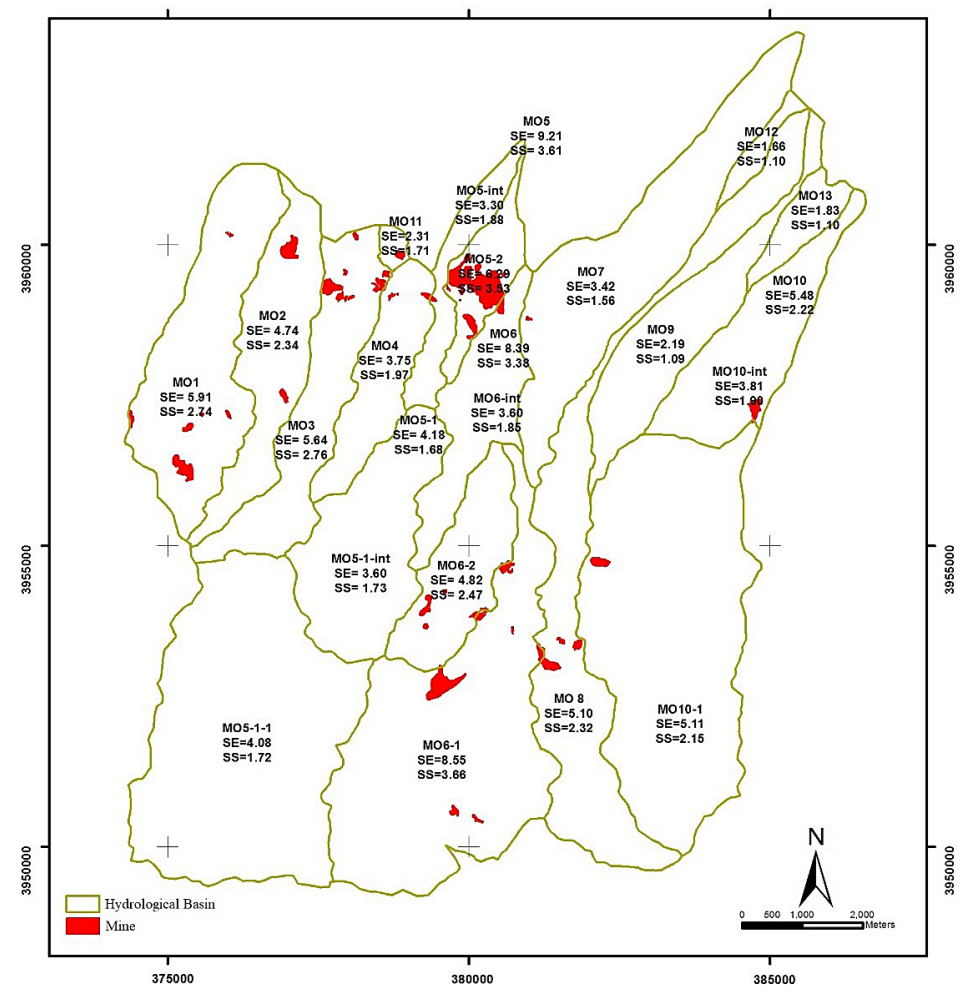

Fig. 6. The special sediment (SS) and special erosion (SE) of hydrological basins based on the MPSIAC model in Moradbigloo watershed in Iran

\section{DISCUSSION}

In order to better understand the processes involved and help inform decision-makers regarding mining-related soil erosion problems, this research mainly employed the LUIM method to investigate the factors contributing to the risk of soil erosion by taking its both Likelihood and Consequence into account. In this study, the management and susceptibility factors serve as two critical factors to estimate the risk of soil erosion. The impact of the land use management on soil erosion has been researched extensively in the soil erosion studies, while susceptibility is a relatively new and complicated concept suffering from lack of a generally accepted method. Consistent with this study, Pintaldi et al. (2018) used runoff to evaluate the soil susceptibility to erosion. Chen et al. (2018), however, found that the vegetation cover is a critical factor in determining the susceptible areas to soil erosion. Drawing from these studies and considering the factors involved in the LUIM model, slope, runoff, and NDVI (as a proxy depicting vegetation biomass) were used to identify the susceptibility to soil erosion.

The abandoned surface mining areas were found to exhibit the highest Likelihood of soil erosion in the region, since they are left without any legislation, forcing them to implement postmining rehabilitation plans. Natural rehabilitation, as the only available option, in this case, occurs slowly and is inefficient in the mining areas where soil has lost much of the surface layer and becomes heavily compacted by the movement of mining vehicles. In this condition, runoff cannot easily penetrate and instead flows while transferring sediments. The abandoned rainfed areas also obtained a high risk of Likelihood where soil is mostly plowed to the slope direction and heavily compacted, impeding the natural vegetation establishment. As shown in Figure 3, other LU/LCs exhibited a low likelihood of soil erosion. In addition to the findings of this research, the studies in this field have stated difficulties in re-establishment of the native vegetation cover in post-mining landscapes, where the essential nutrients of soil have been significantly eliminated (Kleeberg et al., 2008). Hence, having a compacted soil which is devoid of essential nutrients to help vegetation to re-establish, the mining areas would have even a higher level of Likelihood to soil erosion.

Soil sensitivity is associated with a wide array of factors but is perceived to be more associated with soil depth. Soil sensitivity to 
erosion, a measure of soil resilience to and recovery from erosion, was found to be relatively low in the region. Contrary to this, the study area had a high asset value for locals owing to the good productivity of steep rangelands. The mining areas, which obtained a high likelihood of soil erosion, fell into the low Value class both in terms of environmental and socioeconomic factors. The integrated map of soil sensitivity and LU/LC values showed that the majority of the region, especially the mining areas and steep rangelands, is exposed to a high level of soil erosion-related Consequences. As a downside, LUIM failed to distinguish between the mining, rangelands, garden, and irrigated agricultural lands as well as some parts of the rainfed areas, which were classified as high Consequence. In this regard, Gunawan (2018) discussed that the soil erosion-related consequences of mining activities are higher than other land use activities and require immediate post-mining rehabilitation plans.

The study region of this research is endowed with rich mineral resources and captured the attention of private mining executives in recent years. While being exempted from Environmental Assessment Impact procedure, and any responsibility to contribute to land rehabilitation, the mineral resources in the region have been increasingly exploited without considering the resulting environmental consequences. Soil erosion is referred to as a major consequence of mining activities (Kim et al., 2012; Wantzen and Mol, 2013), which requires effective efforts to recreate the pre-mining environmental conditions.

The post-mining landscapes create large volumes of materials that are sensitive to erosion, and their rehabilitation requires shaping for optimal erosional stability and ecological integration into the surrounding undisturbed rangeland landscape (Hancock et al., 2019). The waste landform is the result of mining activities, and it is another source of soil erosion and sedimentation in the study area. These landforms should be stable for an extended time period. The acceptable erosion rates for mine waste landform rehabilitation should be determined. Howard and Loch (2019) suggested an approach to link the erosion thresholds to the waste material's physical properties and measure acceptable erosion rates for this landform. The adverse environmental impacts that may result from landform failure should also be assessed carefully.
Mining causes an anthropogenic change in the soil structure. It has a profound impact on the ecosystem function, including soil stability, infiltration, nutrient cycling, groundwater or surfacewater seepage, and the stability by surface weathering. A landscape function analysis can be used efficiently to assess the landscape function of the post-mining lands (Putra and Aryanti, 2017).

The results of MPSIAC indicated that erosion risk in hydrological basins with mining operations is higher compared to those with no mining operation. In a similar study in the Northwest part of Iran conducted by Hamzeghochi (2015), annual sedimentation was significantly different between sub-basins with mining operations $\left(731.84 \mathrm{~m}^{3}\right)$ compared to sub-basins with no mining activities $\left(667 \mathrm{~m}^{3}\right)(P<0.05)$.

Although a decline in the vegetation cover was identified before and after mining activities in this study area, other factors such as converting rangeland to rainfed agriculture, heavy grazing, and prolonged drought are effective in altering the vegetation composition and decreasing vegetation cover. The effects of grazing are more profound in the areas close to watering points and villages, but the drought conditions may influence the whole parts of the study area. Drought may accelerate the effects of grazing on vegetation if ranchers do not decrease their livestock numbers. Although the conversion of rangeland into rainfed agriculture occurred by locals to achieve more and immediate income from agricultural products (Baranian Kabir et al., 2017), many parts of these areas are faced severe ecological limitations (e.g., low soil depth, high land slope, etc.). These limitations lead to dry farmland abandonment in many cases in this area over a few years and cause a decline in the vegetation cover.

The LUIM approach is superior to methods such as MPSIAC to assess the soil erosion risk because it considers the impacts of soil erosion into account. The result of erosion likelihood is relatively comparable to MPSIAC results, while its consequences never assessed in similar methods.

The approach used in this study has a great potential to inform policy-makers and the regional catchment authorities to assess the impacts of unsustainable land management (e.g., converting rangelands to mining area or rainfed agriculture). Increasing soil erosion risk, declining soil and water quality, and losing ecosystems function may result from such LU/LC change (Aneseyee et al., 2020; Mariye et al., 2020). The 
unsustainable land-use change was more likely to increase a subsequent investment in protection, rehabilitation, and restoration. The methodology used in this study can assist policy-makers for comprehensive catchment management around the world and may support action plans for particular resource management issues such as erosion, salinity, nutrients, soil quality, and biodiversity (MacEwan et al., 2004).

\section{CONCLUSION}

A LUIM model, in conjunction with MPASIC, was employed in this research to investigate the risk of soil erosion in a mining-dominated landscape. Using the LUIM model, we differentiated between two different but complementary concepts that are related to the risk of soil erosion: Likelihood and Consequence. According to the results of this research, all mines of the region were characterized as the areas with a high risk of soil erosion because, despite their significant impacts on soil erosion (captured by both LUIM and MPASIAC), they have a very low incomegenerating potential for the local communities. Although the LUIM model provided useful insights regarding soil erosion in the region, it failed to prioritize the regions that were classified in a specific erosion class. For instance, mining areas, together with parts of rangeland and rainfed lands, were classified as the areas with a high occurrence risk of soil erosion which may reduce their applicability in the formulation of land use management and planning objectives.

\section{Acknowledgement}

The authors would like to thanks Islamic Azad University for their support.

\section{REFERENCES}

1. Abdulkadir T.S., Muhammad R.U.M., Wan Yusof K., Ahmad M.H., Aremu S.A., Gohari A. and Abdurrasheed A.S. 2019. Quantitative analysis of soil erosion causative factors for susceptibility assessment in a complex watershed. Cogent Engineering, 6(1), art. No. 1594506.

2. Aneseyee A.B., Elias E., Soromessa T. and Feyisa G.L. 2020. Land use/land cover change effect on soil erosion and sediment delivery in the Winike watershed, Omo Gibe Basin, Ethiopia. Science of The Total Environment, art. No. 138776.
3. Bakker M.M, Govers G., van Doorn A., Quetier F., Chouvardas D., Rounsevell M. 2008. The response of soil erosion and sediment export to land-use change in four areas of Europe: the importance of landscape pattern. Geomorphology, 98, 213-226.

4. Baranian Kabir E., Bashari H., Mosaddeghi M.R. and Bassiri M. 2017. Soil aggregate stability and organic matter as affected by land-use change in central Iran. Archives of Agronomy and Soil Science, 63(13), 1823-1837.

5. Borrelli P., Robinson D.A., Fleischer L.R., Lugato E., Ballabio C., Alewell C., Meusburger K., Modugno S., Schütt B., Ferro V. 2017. An assessment of the global impact of 21 st century land use change on soil erosion. Nature communications, 8, 1-13.

6. Cerdan O., Govers G., Le Bissonnais Y., Van Oost K., Poesen J., Saby N., Gobin A., Vacca A., Quinton J., Auerswald K, 2010. Rates and spatial variations of soil erosion in Europe: a study based on erosion plot data. Geomorphology, 122, 167-177.

7. Chen H., Zhang X., Abla M., Lü D., Yan R., Ren Q., Ren Z., Yang Y., Zhao W., Lin P. 2018. Effects of vegetation and rainfall types on surface runoff and soil erosion on steep slopes on the Loess Plateau, China. Catena, 170, 141-149.

8. Clark R., MacEwan R., Robinson N., Hopley J. 2010. Remote sensing of land cover and land management practices affecting wind erosion risk in NW Victoria, Australia. 19th world congress of soil science, soil solutions for a changing world.

9. Colazzo M., Niell S., Pareja L., Cesio V., Heinzen H. 2017. The influence of different soil types in the pesticide residue analysis method performance. Reports of the DBG.

10. Demir S., Oğuz İ., Özer E. 2018. Estimation of soil losses in a slope area of Tokat Province through USLE and WEPP Model. Turkish Journal of Agriculture-Food Science and Technology, 6, 1838-1843.

11. Fink J.R., Inda A.V., Bavaresco J., Barrón V., Torrent J., Bayer C. 2016. Adsorption and desorption of phosphorus in subtropical soils as affected by management system and mineralogy. Soil and Tillage Research, 155, 62-68.

12. Gholami V., Booij M., Tehrani E.N., Hadian M. 2018. Spatial soil erosion estimation using an artificial neural network (ANN) and field plot data. Catena, 163, 210-218.

13. Gunawan S. 2018. Direction of mine land reclamation based on geographical condition in Batupasir mining in Rejosari design, Village of Art, Gedangsari District, Regency of Gunungkidul, Diy. Universitas Pembangunan Nasional" Veteran" Yogyakarta.

14. Hancock G.R., Duque J.M., Willgoose G.R. 2019. Geomorphic design and modelling at catchment scale for best mine rehabilitation- The Drayton mine example (New South Wales, Australia). Environmental modelling \& software, 114, 140-151. 
15. Hou X., Shao J., Chen X., Li J., Lu J. 2020. Changes in the soil erosion status in the middle and lower reaches of the Yangtze River basin from 2001 to 2014 and the impacts of erosion on the water quality of lakes and reservoirs. International Journal of Remote Sensing, 41(8), 3175-3196.

16. Howard E.J., Loch R.J. 2019. Acceptable erosion rates for mine waste landform rehabilitation modelling in the Pilbara, Western Australia. In Proceedings of the 13th International Conference on Mine Closure, Australian Centre for Geomechanics, pp. 1545-1560.

17. Kim S-M., Choi Y., Suh J., Oh S., Park H-D., Yoon S-H. 2012. Estimation of soil erosion and sediment yield from mine tailing dumps using GIS: a case study at the Samgwang mine, Korea. Geosystem Engineering, 15, 2-9.

18. Kleeberg A., Schapp A., Biemelt D. 2008. Phosphorus and iron erosion from non-vegetated sites in a post-mining landscape, Lusatia, Germany: Impact on aborning mining lakes. Catena, 72, 315-324.

19. Kuchami-Sardo I., Besalatpour A.A., Bashari H., Shirani H. and Yildiz Ö. 2020. A geographic information system-based land use impact model to map areas with risk for land degradation: Wind erosion as an example. Land Degradation \& Development, 31(9), 1110-1124.

20. Lakhote A.B., Khode B., Baisware E. 2014. Estimation of runoff for agricultural watershed and silt load assessment. International Journal of Innovative Research in Advanced Engineering, 1, 62-69.

21. MacEwan R.J., McNeill J., Clarkson T. 2004. Developing a regional soil health strategy using a land use impact model.'. In SuperSoil'. Proceedings of the International Soil Science Conference 2004, 5-9 December 2004, Sydney, Australia.

22. Mariye M., Mariyo M., Changming Y., Lakew Teffera Z., Weldegebrial B. 2020. Effects of land use and land cover change on soil erosion potential in Berhe district: A case study of Legedadi watershed, Ethiopia. International Journal of River Basin Management, (in print), pp. 1-31.

23. Martín-Moreno C., Martin Duque J.F., Nicolau Ibarra J.M., Hernando Rodríguez N., Sanz Santos M.Á., Sánchez Castillo L. 2016. Effects of topography and surface soil cover on erosion for mining reclamation: the experimental spoil heap at El Machorro Mine (Central Spain). Land Degradation \& Development, 27, 145-159.

24. McNeill J., MacEwan R., Crawford D. 2006. Using GIS and a land use impact model to assess risk of soil erosion in West Gippsland. Applied GIS, 2, 19.1-19.6

25. Noori H., Karami H., Farzin S., Siadatmousavi S.M., Mojaradi B., Kisi O., 2018. Investigation of RS and GIS techniques on MPSIAC model to estimate soil erosion. Natural Hazards, 91(1), 221-238.

26. Ochoa-Cueva P., Fries A., Montesinos P., Rodríguez-Díaz J.A., Boll J. 2015. Spatial estimation of soil erosion risk by land-cover change in the Andes of southern Ecuador. Land degradation \& development, 26, 565-573.

27. Ostovari Y., Ghorbani-Dashtaki S., Bahrami H-A., Naderi M., Dematte J.A.M., Kerry R. 2016. Modification of the USLE $\mathrm{K}$ factor for soil erodibility assessment on calcareous soils in Iran. Geomorphology, 273, 385-395.

28. Pintaldi E., D’Amico M.E., Stanchi S., Catoni M., Freppaz M., Bonifacio E. 2018. Humus forms affect soil susceptibility to water erosion in the Western Italian Alps. Applied Soil Ecology, 123, 478-483.

29. Putra, H.F., Aryanti N.S. 2017. March. Landscape function of post tin-mining land after reclamation in Bangka, Indonesia. In: IOP Conference Series: Earth and Environmental Science, IOP Publishing, Vol. 58, No. 1, p. 012018.

30. Renschler C.S., Harbor J. 2002. Soil erosion assessment tools from point to regional scales - the role of geomorphologists in land management research and implementation. Geomorphology, 47, 189-209.

31. Rousk K., Michelsen A., Rousk J. 2016. Microbial control of soil organic matter mineralization responses to labile carbon in subarctic climate change treatments. Global Change Biology, 22, 4150-4161.

32. Suh J., Kim S.M., Yi H., Choi Y. 2017. An overview of GIS-based modeling and assessment of mininginduced hazards: Soil, water, and forest. International Journal of Environmental Research and Public Health, 14(12), 1463.

33. Toy T.J., Foster G.R., Renard K.G. 2002. Soil erosion: processes, prediction, measurement, and control. John Wiley \& Sons.

34. Verstraeten G., Van Oost K., Van Rompaey A., Poesen J., Govers G. 2002. Evaluating an integrated approach to catchment management to reduce soil loss and sediment pollution through modelling. Soil Use and Management, 18, 386-394.

35. Wang X., Zhao X., Zhang Z., Yi L., Zuo L., Wen Q., Liu F., Xu J., Hu S., Liu B. 2016. Assessment of soil erosion change and its relationships with land use/ cover change in China from the end of the 1980s to 2010. Catena, 137, 256-268.

36. Wantzen K., Mol J. 2013. Soil erosion from agriculture and mining: a threat to tropical stream ecosystems. Agriculture, 3, 660-683.

37. Yin L., Yan Q.W., Bian Z.F. 2016. Evaluation of soil erosion of Liupanshui City based orn evised Universal Soil Loss Equation (RUSLE). Journal of Ecology and Rural Environment, 3, 009.

38. Zhang L., Bai K.Z., Wang M.J., Karthikeyan R. 2016. Basin-scale spatial soil erosion variability: Pingshuo opencast mine site in Shanxi Province, Loess Plateau of China. Natural Hazards, 80, 1213-1230.

39. Zhang L., Wang J., Bai Z., Lv C. 2015. Effects of vegetation on runoff and soil erosion on reclaimed land in an opencast coal-mine dump in a loess area. Catena, 128, 44-53. 